\title{
$\mathrm{S}$ \\ Turismo e Sociedade Revista I UFPR
}

\section{Turismo e participação social no contexto do Circuito Turístico Serras de Ibitipoca, Minas Gerais}

\author{
Tourism and social participation in the context of the Circuito \\ Turístico Serras de Ibitipoca, Minas Gerais
}

Monalisa Barbosa Alves ${ }^{1}$

RESUMO: No âmbito das políticas públicas de turismo no Brasil, uma importante questão que emerge é como responder ao compromisso de participação social frente ao desenvolvimento do turismo. Tendo em vista a necessidade de se avançar em novas reflexões sobre os desafios da participação social no âmbito do turismo, o presente artigo teve como objetivo analisar em que medida a participação, um dos princípios norteadores do Programa de Regionalização do Turismo, se efetiva no contexto do Circuito Turístico Serras de Ibitipoca, Minas Gerais. Trata-se de um estudo de caso fundamentado em uma abordagem interdisciplinar, a partir de análise qualitativa, baseada em pesquisa bibliográfica e documental; pesquisa de campo composta por entrevistas semiestruturadas; e, análise de conteúdo. Os principais resultados revelaram que apesar do tema participação social ser ressaltado nas políticas públicas de turismo, os discursos veiculados estão distanciados das práticas efetivas. A política pública de regionalização do turismo é implementada em Minas Gerais por meio das Instâncias de Governança Regionais denominadas Circuitos Turísticos. No entanto, sob a ótica de análise da participação social, verificou-

1 Doutorado e mestrado em Psicossociologia de Comunidades e Ecologia Social pela Universidade Federal do Rio de Janeiro (UFRJ). Graduação em Turismo pela Universidade Federal de Juiz de Fora (UFJF). E-mail: monalisabarbosa@yahoo.com.br 
se que, que no Circuito Turístico Serras de Ibitipoca, existem diversos desafios para a efetivação de uma gestão participativa e descentralizada tal como proposto pela política, refletindo em uma baixa participação. Aponta-se, portanto, a necessidade de mudanças nos processos que levem ao aumento da participação dos atores locais, o que envolve a governança e pressupõe um processo educativo que vise sensibilizar e conscientizar a partir da realidade local.

Palavras-chave: Turismo; Participação Social; Políticas Públicas de Turismo; Desenvolvimento Local

ABSTRACT: Within the context of the tourism public policies in Brazil, an important question that emerges is how to answer to the commitment to social participation in the face of tourism development. In order to advance on new reflections on the challenges of social participation in the field of tourism, this article aimed to analyze how the participation occurs, since it is one of the guiding principles of the Tourism Regionalization Program, if it is effective in the context of the Circuito Turístico Serras de Ibitipoca, Minas Gerais, Brazil. This is a case study based on an interdisciplinary approach, based on qualitative analysis, bibliographic and documentary research; field research composed of semi-structured interviews; and, content analysis. The main results revealed that although the theme of social participation is highlighted in tourism public policies, the speeches are far away from the effective practices. The public policy of tourism regionalization is implemented in Minas Gerais through the Regional Governance Instances known as Circuitos Turísticos. However, from the perspective of social participation analysis, it was found that, within the Circuito Turístico Serras de Ibitipoca, there are several challenges for the implementation of a participatory and decentralized management as proposed by the policy, reflecting a low participation. Therefore, there is a need for changes in the processes that lead to an increase in the participation of local actors, which involves governance and requires an educational process that aims to sensitize and raise awareness based on the local reality.

Keywords: Tourism; Social Participation; Tourism Public Policies; Local Development. 


\section{INTRODUÇÃO}

O turismo constitui um fenômeno sociocultural complexo que abrange dimensões econômicas, sociais, culturais, ambientais e políticas. Defender a viabilidade do desenvolvimento do turismo em bases sustentáveis, visando o bem comum e a melhoria da qualidade de vida da população local implica colocar a participação social no cerne do debate.

Para Hô (2006), o desenvolvimento encontra seu impulso fundador nas necessidades e nas aspirações dos indivíduos como coletividades, nos fins a que eles se propõem e nos projetos que os concretizam. Neste sentido, o autor aponta a participação social como premissa para qualquer projeto de desenvolvimento. Segundo Irving (2018), experiências bem-sucedidas de participação social podem ter um papel significativo na mudança de mentalidade dos atores envolvidos, no sentido de corresponsabilidade e no exercício de cidadania, essenciais ao desenvolvimento efetivo das sociedades humanas.

Contudo, a participação é fundamental para que se alcance um desenvolvimento em acordo com a dinâmica, a realidade e as especificidades locais. Tal participação é apontada no discurso das políticas públicas de turismo (PRT 2007; PNT 2007/2010; PNT 2013/2016; PNT 2018/2022). No entanto, como essa participação se efetiva no âmbito das localidades?

Criado em 2004, como estratégia de gestão do turismo no país, o Programa de Regionalização do Turismo (PRT) tornou-se o principal programa da política adotada no Plano Nacional de Turismo (PNT) tendo como princípios a descentralização, a integração, a participação e a sustentabilidade ambiental, sociocultural e econômica (BRASIL, 2007). Em Minas Gerais, a regionalização se consolidou por meio dos Circuitos Turísticos que possuem o objetivo comum de desenvolver o turismo de forma integrada (MINAS GERAIS, 2014).

Assim, tendo em vista a importância de se avançar em novas reflexões sobre os desafios na gestão participativa do turismo o presente artigo teve como objetivo analisar em que medida a participação, um dos princípios norteadores do PRT, se efetiva no âmbito do Circuito Turístico Serras de Ibitipoca.

Trata-se de um estudo de caso fundamentado em uma abordagem interdisciplinar, a partir de análise qualitativa, baseada em pesquisa bibliográfica e documental. Foi realizada uma pesquisa de campo composta por entrevistas semiestruturadas, e os resultados obtidos a partir da análise de conteúdo.

Para avançar no objetivo proposto, o artigo foi estruturado em cinco seções. Nesta introdução, se busca contextualizar a problemática em foco. A segunda seção visa refletir, teoricamente, sobre turismo, desenvolvimento e participação social. A terceira seção descreve os procedimentos metodológicos da pesquisa. Em seguida, apresenta-se os resultados e a análise da participação social no contexto do Circuito Turístico Serras de Ibitipoca. A quinta e última seção apresenta as considerações finais da análise proposta. 


\section{TURISMO, DESENVOLVIMENTO E PARTICIPAÇÃO SOCIAL}

O turismo se constitui um fenômeno sociocultural complexo. Representa uma prática de grande importância no contexto socioeconômico de várias localidades, condição suficiente para despertar nos diversos governos o interesse pelo seu desenvolvimento. No entanto, não se deve entender o turismo como única ferramenta capaz de resolver as mazelas socioeconômicas de um território qualquer, mas "como [mais] uma das alavancas que podem impulsionar o desenvolvimento regional e local" (CRUZ, 2002, p. 43).

O potencial de produzir efeitos positivos é utilizado como justificativa para investimentos em projetos e formulação de políticas de incentivo ao turismo. Destacase a geração de emprego e renda, o desenvolvimento de serviços e infraestrutura, a conservação e valorização do ambiente e do patrimônio histórico e cultural.

Porém, o planejamento e o desenvolvimento inadequado do turismo mitigam essa capacidade e intensificam seus efeitos negativos. Quando o desenvolvimento do turismo não é planejado e discutido suficientemente pela comunidade pode ocorrer descaracterização das tradições culturais, substituição das antigas atividades produtivas da localidade, alterações no meio ambiente, alterações no modo de vida dos moradores, conflitos, dentre outros.

Segundo Irving (2006), um dos grandes desafios ainda é o 'fazer coletivo' e o entendimento da participação social como garantia ética de sustentabilidade em projetos de conservação de recursos renováveis e/ou desenvolvimento. Sachs (2004) ressalta a necessidade de se revisitar a ideia de desenvolvimento, ou seja, de torná-lo mais operacional.

No entanto, salienta-se que desenvolvimento não deve ser confundido com crescimento econômico, visto que, muitas vezes, este não muda a realidade local, não reduz a pobreza, não atenua as desigualdades e não visa a melhoria da qualidade de vida da população.

No âmbito das políticas, a lógica da racionalidade e do mercado, se sobressai, muitas vezes, sobre a lógica das necessidades reais da população. De acordo com Irving (2018, p. 63),

\footnotetext{
as necessidades de uma sociedade não se restringem as demandas de ordem econômica. As diversas dimensões políticas, sociais, culturais e ambientais representam, também eixos essenciais do processo. Nesse sentido, o compromisso de participação social nos processos decisórios constitui prérequisito para o desenvolvimento, pois apenas a própria sociedade é capaz de identificar as suas necessidades.
}

Santos (2005, p.45) corrobora ao afirmar que a concepção que simplifica e interpreta desenvolvimento como crescimento acaba por implicar na marginalização de outros objetivos sociais, econômicos e políticos, tais como a participação na tomada de decisões e a distribuição equitativa dos frutos do desenvolvimento. 
É importante ressaltar que o desenvolvimento se refere a uma realidade que é complexa e dinâmica, constituindo uma diversidade de padrões e caminhos sociais e reafirmando as peculiaridades de uma dada sociedade (IRVING, 2018). Assim, as regiões que seguem um padrão imitativo não percebem que precisam buscar seu desenvolvimento a partir de sua história, sua cultura e seus recursos próprios (SACHS, 1998).

Nesta perspectiva, o desenvolvimento exige o protagonismo local. Para Sen (2000) o principal meio e o principal fim do desenvolvimento é possibilitar a expansão da liberdade dos indivíduos para que estes possam encontrar melhores condições de vida, podendo agir sobre os fatores que não estão em acordo com uma vida digna e de qualidade.

Tal abordagem tem como premissa básica a importância da liberdade humana e o estímulo à condição de agente do indivíduo enquanto sujeito ativo de mudanças e não somente como receptor passivo de benefícios. No entanto, o autor ressalta que existe uma complementaridade entre a condição de agente individual e as disposições sociais, onde a liberdade encontra-se limitada pelas oportunidades sociais, políticas e econômicas às quais o indivíduo teve acesso (SEN, 2000).

O desenvolvimento deve partir das próprias necessidades latentes das comunidades, na busca de alternativas que propiciem benfeitorias em todos os âmbitos - econômico, social, cultural, ambiental - e criar condições e oportunidades para que a população local participe efetivamente desse processo.

Pinheiro, Maracajá e Chim-Miki (2020) apontam que é por meio da participação social no processo de decisão que uma sociedade define suas verdadeiras carências e aponta suas peculiaridades para que a condução do processo de desenvolvimento seja compatível com as características locais. Os autores destacam a necessidade de um arranjo institucional local que gerencie o processo de desenvolvimento do setor turístico, considerando os saberes das populações.

Endres e Pakman (2019) acrescentam que desde os processos de redemocratização ocorridos em vários pontos do mundo, a orientação por mudanças institucionais que permitissem maior participação social na implementação de políticas públicas faz-se premente. Para os autores é uma trajetória que tende a ir de ações centralizadas para estruturas e mecanismos mais descentralizados e participativos, de uma conjuntura que privilegia o grande capital para uma que possibilite a ampliação de valores locais e endógenos.

Para Sachs a participação ocupa bastante espaço no discurso sobre desenvolvimento. No entanto, a realidade

manifesta muitas vezes a imposição de estratégias elaboradas no escalão central. A reabilitação da abordagem inversa, que privilegia as iniciativas vindas de base, deve ser providenciada, especialmente no que diz respeito à identificação das necessidades reais da população e à hierarquia das urgências. Para tanto, deverá ser fortalecida a capacidade das populações para responsabilizarem-se por boa parte das decisões que Ihes dizem 
respeito (SACHS, 1995, p.48).

Diante deste contexto, torna-se necessário apreender novas formas de organização e participação em meio a relações diversificadas com a gestão da democracia, o fortalecimento da cidadania e a busca de objetivos comuns. Este processo envolve a governança e supõe políticas de descentralização, experiências de cogestão, instauração de conselhos e implantação de mecanismos de participação.

Endres e Pakman (2019) citam como exemplo a variedade de espaços de participação como fóruns, conselhos e comitês. Destacam que essas experiências contribuem para o exercício da participação e podem transformar a realidade regional e local. Acredita-se que oportunizar as comunidades a participar efetivamente das atividades que visem o desenvolvimento local, significa proporcionar condições para que elas mobilizem seu próprio potencial, sejam agentes sociais em vez de sujeitos passivos e passem a gerir as atividades que afetam sua vida (SANTOS; AVILA, 2017).

No âmbito do turismo, a questão que emerge é qual modelo de turismo se almeja e que medidas de planejamento poderiam assegurar uma nova concepção baseada na valorização e na percepção do local como ponto focal de novas iniciativas (IRVING, 2003). Neste sentido, Irving (1999) afirma que é necessário construir um modelo endógeno de desenvolvimento turístico, capaz de ousar na inovação e de assimilar o compromisso de engajamento do ator social local, como ponto focal de sustentabilidade; o que requer o desenvolvimento de metodologias capazes de lidar com a subjetividade e não apenas centradas na racionalidade. Contudo, ressaltase a importância dos protagonistas dos destinos serem sujeitos e não objetos do processo.

\subsection{A PARTICIPAÇÃO E A REDEFINIÇÃO DOS ATORES DO DESENVOLVIMENTO}

Diversos são os pontos de vista sobre o tema da participação, assim como as utilidades que este pode ter. Para Bordenave (2013, p. 14) "a enumeração das contribuições da participação poderia levar a um conceito puramente instrumental, com o perigo de que se veja nela algo para ser dirigido, manipulado ou explorado quanto a seus resultados". É necessário, portanto, desvincular-se desta abordagem da participação e analisá-la enquanto processo capaz de gerar uma nova dinâmica de organização social e envolvimento em questões relativas ao bem comum.

Para Loureiro, Marcus e Franca (2003), a participação pode ser definida como um "processo social que gera a interação entre diferentes atores sociais na definição do espaço comum e do destino coletivo". Defender a participação nestes processos é reconhecer a capacidade dos indivíduos de construírem seus próprios caminhos e de intervirem em suas realidades. Portanto, o compromisso de participação social pode representar uma importante possibilidade de substituição de modelos tradicionais centralizadores e desconectados das realidades locais (IRVING, 2003).

Participação é fazer parte, tomar parte ou ter parte. No entanto é possível fazer parte sem tomar parte, e aí consiste a diferença "entre a participação passiva 
e a participação ativa, a distância entre o cidadão inerte e o cidadão engajado" (BORDENAVE, 2013, p. 22). Para Bordenave (2013), a participação não consiste na recepção passiva dos benefícios da sociedade, mas, na intervenção ativa na sua construção. Assim, assume caráter de processo coletivo transformador. Remete a protagonismo social, a solidariedade, e, juntamente com a descentralização das decisões mostra-se como o caminho mais adequado para enfrentar os problemas graves e complexos dos países em desenvolvimento.

O mesmo autor ressalta que é possível falar de processos de micro e macroparticipação. O cidadão, além de participar em nível micro na família, na escola, no trabalho, na comunidade, nas associações, dentre outras, também participa em nível macro quando intervém nas lutas sociais, econômicas e políticas de seu tempo. É na microparticipação que a práxis participativa e a educação para a participação se desenvolvem e se ampliam (BORDENAVE, 2013).

Nesta perspectiva, Góis (2005, p. 150) enfatiza que a participação implica em "que a pessoa influenciada pelas condições e situações histórico-sociais que em geral lhe afetam materialmente e ou existencialmente, decide participar de atividades socialmente significativas no lugar em que vive". Para Bordenave (2013) é na comunidade que se estruturam, da melhor forma, as relações democráticas.

No entanto, Bordenave (2013) afirma que a participação não é um conteúdo que se possa transmitir, mas uma mentalidade e um comportamento com ela coerente; é uma vivência coletiva e não individual. O exercício da participação implica mudança de uma cultura de passividade e de dependência, um processo que demanda tempo. Portanto, a participação precisa ser construída, incentivada, refeita e recriada.

Demo (2001) ressalta que para o completo exercício da cidadania é preciso que a comunidade seja educada para ação da participação conhecendo seus direitos e seus deveres a partir da

noção de sujeito social, não de objeto social, a noção de direitos e deveres, sobretudo os fundamentais tais como direitos humanos, a noção de democracia como forma de organização socioeconômica e política, a noção de liberdade, igualdade, comunidade (DEMO, 2001, p. 52-53).

Neste sentido, Bordenave (2013) acrescenta que a participação pode ser considerada um dos aspectos fundamentais do desenvolvimento pessoal e coletivo. Possibilita ao indivíduo autonomia e percepção sobre problemas sociais vividos, tornando-Ihes conscientes de seu papel como protagonistas para compor uma análise crítica sobre a realidade social local. Assim, participar significa dividir as responsabilidades na construção coletiva de um processo que objetiva fortalecer a sociedade civil para a construção de caminhos que apontem para uma nova realidade social, mudanças de contextos adversos e transformação social (GOHN, 2008).

O compromisso de participação social constitui o elemento central no novo paradigma de desenvolvimento das sociedades humanas (IRVNG, 2018). No âmbito do planejamento e gestão do turismo a efetiva participação das comunidades locais 
é essencial. Ela é conhecedora e vivencia sua realidade imediata, podendo identificar problemas e necessidades, avaliar alternativas, desenvolver estratégias e buscar soluções para problemas identificados, sugerindo caminhos que levem à melhoria da qualidade de vida e ao fortalecimento da cultura local.

Como instrumento central para promover a participação social no desenvolvimento turístico, o MTUR (2007) propôs um modelo de gestão pública descentralizada e participativa promovendo Instâncias de Governança Regionais. Estas são compreendidas como instâncias democratizantes do processo de gestão, uma forma de incorporar as reivindicações de cunho democrático participativo na gestão do turismo.

\section{METODOLOGIA}

Para o desenvolvimento do trabalho adotou-se uma abordagem qualitativa. Para Minayo (2009), a pesquisa qualitativa responde a questões muito particulares, em um nível de realidade que não pode ou não deveria ser quantificado, pois seu objeto de estudo dificilmente pode ser traduzido em números e indicadores quantitativos.

O método utilizado para o desenvolvimento da presente pesquisa foi o estudo de caso. Tal procedimento "assemelha-se à focalização sobre um experimento que se busca compreender por meio de entrevistas, observações, uso de banco de dados e documentos" (MINAYO, 2008, p.164). Com o intuito de dar conta do objetivo proposto, o trabalho dividiu-se em três fases: pesquisa bibliográfica e documental; pesquisa de campo baseada em entrevista semiestruturada; e, análise de conteúdo.

A primeira etapa da pesquisa consistiu em um levantamento bibliográfico sobre à temática do turismo, políticas públicas de turismo, desenvolvimento e participação social, visando a construção do aporte teórico do estudo. Na contextualização do Circuito Turístico Serras de Ibitipoca foi realizado levantamento documental junto a Associação do Circuito Turístico Serras de Ibitipoca, Secretaria de Turismo de Lima Duarte, Secretaria de Turismo de Minas Gerais (SETES) e Ministério do Turismo. Esta fase permitiu a coleta de dados secundários e diagnosticar o campo de pesquisa.

A segunda etapa da pesquisa consistiu no trabalho de campo. Para o levantamento dos dados foi utilizado como instrumento a entrevista. Minayo (2009) as considera como "conversas com finalidade", que visa construir informações pertinentes com o objeto de pesquisa. As entrevistas foram do tipo semiestruturadas permitindo aos entrevistados discorrer mais amplamente sobre o tema em questão sem se prender a indagação formulada (MINAYO, 2009). Foram realizadas doze entrevistas, presencialmente e por email no período de janeiro de 2014 a março de 2015, a partir de um roteiro de entrevistas. Utilizou-se códigos para identificar os sujeitos entrevistados.

Os sujeitos incluídos na presente pesquisa relacionam-se diretamente com o turismo, e mais especificamente com o Circuito Turístico Serras de lbitipoca, sendo estes, representantes da Associação do Circuito Turístico Serras de Ibitipoca, do 
Instituto Estadual de Florestas, da Secretaria de Turismo de Minas Gerais e do MTUR. É importante destacar, como limitação do presente estudo, a dificuldade de contato com representantes das secretarias ou departamentos de Turismo dos municípios pertencentes ao Circuito. No entanto, os dados de campo permitiram estabelecer um eixo de reflexão sobre a participação no contexto do Circuito Turístico Serras de Ibitipoca.

Por fim, visando a sistematização e análise dos dados utilizou-se a análise de conteúdo. Devido ao tipo de trabalho proposto, a modalidade de análise de conteúdo selecionada foi a análise temática. Para esta modalidade o conceito central é o tema, podendo este ser graficamente apresentado por meio de uma palavra, uma frase, um resumo (MINAYO, 2009). Como eixos norteadores partiu-se dos seguintes temas, que foram analisadas a partir de relatos dos sujeitos da pesquisa: turismo e o processo de desenvolvimento; participação social; e, desafios no contexto do Circuito Turístico Serras de Ibitipoca.

\section{ANÁLISE DO CIRCUITO TURÍSTICO SERRAS DE IBITIPOCA}

O presente artigo não pretende descrever a trajetória da política pública de turismo brasileira devido à necessidade de delimitação da discussão em torno da problemática proposta. No entanto, é importante destacar que, em 2004, o MTUR adotou a regionalização como diretriz para o desenvolvimento do turismo no país, implementando em todo o território nacional o PRT.

O PRT é o modelo de ordenamento político-territorial referência para todas as ações do MTUR. Dentre os objetivos propostos visa promover o diálogo, a discussão e a tomada de decisão participativa entre os atores envolvidos com o desenvolvimento do turismo regional, além de promover articulações e integração dos atores locais e regionais (BRASIL, 2013). O Plano Nacional de Turismo 2018-2022 apresenta como uma de suas diretrizes o fortalecimento da regionalização do turismo (BRASIL, 2018).

Em Minas Gerais, a regionalização se consolidou por meio de Circuitos Turísticos que possuem o objetivo comum de desenvolver o turismo de forma integrada (MINAS GERAIS, 2014). Os Circuitos Turísticos mineiros são Instâncias de Governança Regionais e se configuram como o principal interlocutor dos governos municipais junto ao governo estadual e federal, orientando e coordenando, em parceria com os Conselhos Municipais, a execução da política de turismo junto à cadeia produtiva local (MINAS GERAIS, 2020). Para o desenvolvimento da presente pesquisa adotouse como Estudo de Caso o Circuito Turísticos Serras de Ibitipoca.

O Circuito Turístico Serras de Ibitipoca foi reconhecido como Instância de Governança Regional pela Setur em 2006. Localiza-se na Zona da Mata Mineira, na Serra da Mantiqueira, e é formado pelos municípios de Bias Fortes, Bom Jardim de Minas, Ibertioga, Lima Duarte, Pedro Teixeira, Rio Preto, Santa Rita de Ibitipoca, Santa Rita de Jacutinga, Santana do Garambéu e Olaria. 


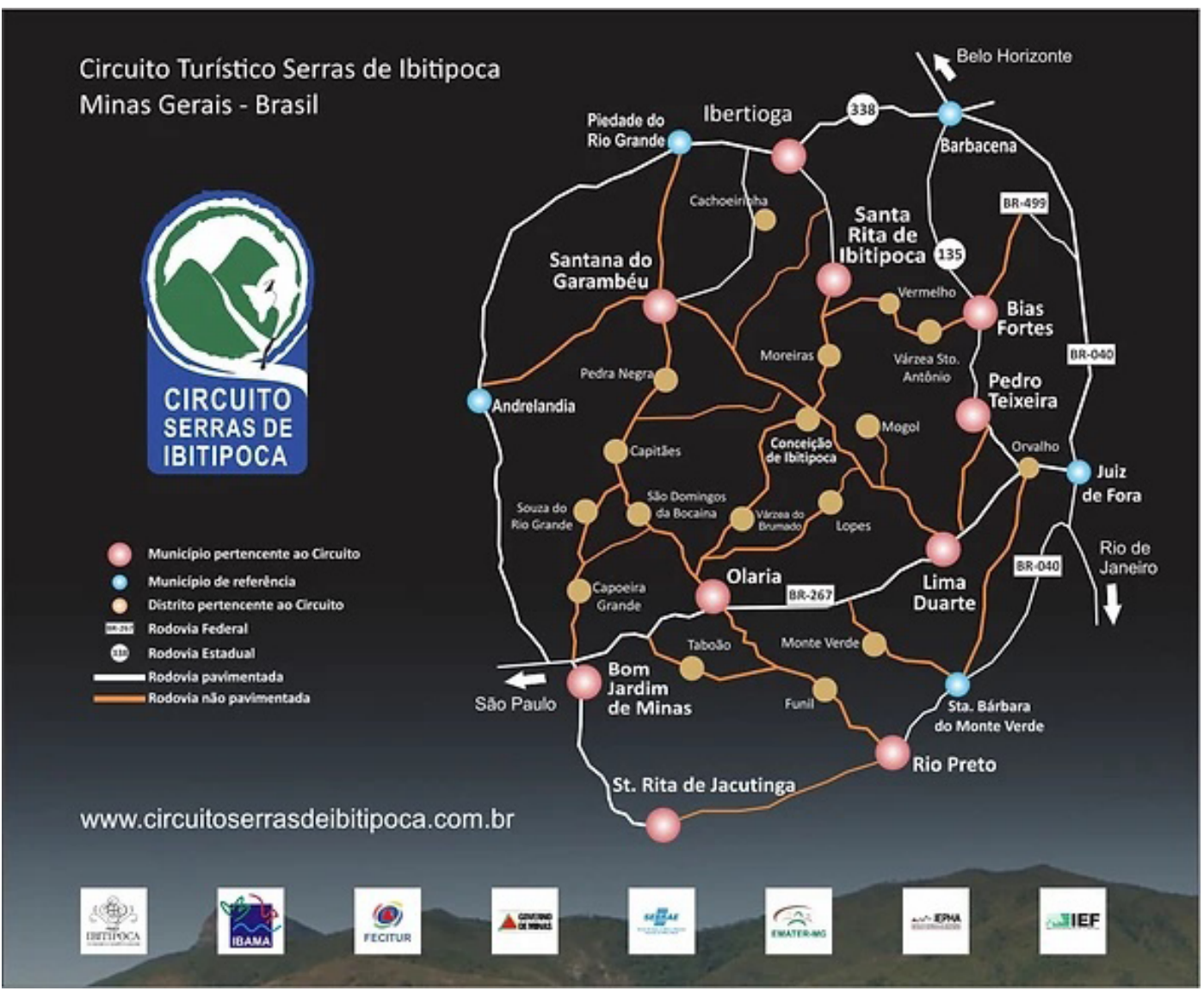

FONTE: Circuito Serras de Ibitipoca, 2020

O Circuito é caracterizado por suas belezas naturais composta por cachoeiras, serras e rica biodiversidade. Tem como atrativo principal o Parque Estadual de Ibitipoca, localizado no município de Lima Duarte. Mas os atrativos turísticos não estão restritos ao parque. Todos os municípios que compõem o Circuito Turístico Serras de Ibitipoca possuem cachoeiras, grutas e curiosas formações rochosas. 0 Circuito também apresenta características peculiares e especificidades típicas de uma região mineira, tais como a culinária, o artesanato e as festas religiosas. É uma região cercada por história, com suas vilas, povoados e capelas.

O sujeito $A$ ao refletir sobre o processo de desenvolvimento do turismo no âmbito do Circuito Turístico Serras de Ibitipoca destaca como aspecto positivo "a vinda de mais recursos, dinheiro para a região". No entanto, é importante ressaltar que a geração de emprego e renda, muita das vezes destacadas como benefício, pode significar para a população local desigualdade e exclusão, opondo-se ao discurso usualmente apresentado de distribuição dos benefícios socioeconômicos e inclusão social.

No contexto do Circuito Turístico Serras de Ibitipoca, o sujeito B destaca que 
o papel do Circuito Turístico é estimular a participação coletiva de atores envolvidos no desenvolvimento do turismo, visando uma construção participativa que priorize o benefício coletivo em detrimento ao interesse particular. De acordo com o Mtur no documento Introdução à Regionalização do Turismo (BRASIL, 2007, p. 31) a participação seria, antes de tudo, um processo de construção da cidadania, sendo que

a plena participação só acontecerá em clima de respeito à diversidade e no consenso das propostas, de modo a incluir todos os interesses. O que queremos dizer é que o conhecimento e a sabedoria locais, as habilidades e as experiências, a cultura e suas práticas devem ser ouvidas e consideradas.

Portanto, teoricamente, a participação é assegurada nos documentos oficiais. Contudo, o sujeito $C$ relata que muitas vezes não acontece na prática. $O$ entrevistado cita a contratação de empresas de consultoria que, muitas vezes, não tem compromisso com o desenvolvimento do turismo, mas em fazer o município receber o ICMS1.

Irving (2018), ressalta que muitas vezes processos participativos são colocados em prática apenas para atender a algumas salvaguardas de projetos ou para o cumprimento de condicionantes para o seu financiamento. Assim, quando as peculiaridades regionais, de ordem econômica, sociocultural e ambiental são negligenciadas na concepção de projetos turísticos, consequências nefastas resultam, tanto em relação aos resultados econômicos, quanto aos impactos socioculturais e ambientais sobre as localidades turísticas (IRVING, 2018).

De acordo com alguns entrevistados um dos grandes motivos dos municípios participarem do Circuito Turístico é o ICMS Turístico. Segundo o sujeito D para o município "receber o ICMS Turístico um dos critérios que mais valem ponto é ele estar com convênio assinado e em acordo financeiramente com o Circuito". O sujeito E afirma que "com o ICMS Turístico os municípios ficam mais ativos". A partir de tais relatos destaca-se que este pode ser considerado um mecanismo de indução e alinhamento de políticas públicas.

O sujeito F destaca o papel dos Conselhos Municipais de Turismo (COMTUR's) enquanto instrumento de participação. No entanto, estes conselhos ainda não se efetivaram em todos os municípios do Circuito. Segundo ele no Circuito Turístico Serras de Ibitipoca os conselhos começaram "a ser formado[s] de dois, três anos pra cá, então nem todos os municípios têm conselho”. Tal fato dificulta a participação e integração efetiva do município no Circuito Turístico Serras de Ibitipoca.

1 O ICMS Turístico (Imposto sobre Circulação de Mercadorias e Serviços) atua como motivador e catalisador de ações, visando estimular a formatação/implantação de programas e projetos municipais voltados para o desenvolvimento turístico sustentável, em especial os que se relacionam com as políticas para o turismo dos Governos Estadual e Federal (MINAS GERAIS, 2014). 
Contudo, em 2018, a Portaria n 192 do MTur estabeleceu que para integrar o Mapa do Turismo Brasileiro as regiões turísticas deverão observar alguns critérios, dentre estes, comprovar a existência de uma Instância de Governança Regional (conselho, fórum, comitê, associação) responsável por sua gestão. Quanto aos municípios, a Portaria aponta que para integrar uma Região Turística do Mapa, o município deverá, dentre outros critérios, comprovar a existência de Conselho Municipal de Turismo ativo.

Para Pinheiro, Maracajá e Chim-Miki (2020) a análise dos espaços de discussão e tomada de decisão, como os Conselhos de Turismo são vitais. Segundo os autores estas iniciativas precisam ser estabelecidas em âmbito local e a participação deve ser antecedida de um empoderamento local, através da construção e difusão do conhecimento.

De acordo com Fratucci (2009) a articulação de dois ou mais municípios circunvizinhos em uma região turística só é possível de ocorrer de forma consistente, se cada um deles já estiver com sua estrutura local minimamente organizada. Para o autor,

\footnotetext{
a articulação regional necessita ser precedida por um processo de articulação municipal, segundo um processo endógeno iniciado na escala local. A não observância desse ponto está diretamente relacionada com a continuidade do poder de decisão do centro, ou seja, a descentralização ocorre gerenciada pelo Estado e não como fruto de processos participativos endógenos consistentes e duradouros. (...) o que pode motivar ou desmotivar a ação e a participação dos agentes locais (FRATUCCI, 2009, p. 406).
}

Nesta perspectiva, retoma-se a ideia de que se o desenvolvimento destas regiões não partir de uma gestão integrada e participativa, a estratégia proposta servirá apenas para planejamentos políticos e administrativos exógenos.

Sachs (2004) destaca a necessidade de se criar espaços para o exercício da democracia direta, na forma de foros de desenvolvimento local que evoluam na direção de formar conselhos. Para o autor, estes espaços podem ser compreendidos como forma a empoderar as comunidades para que elas assumam um papel ativo e criativo no desenho do seu futuro.

Outra questão apontada por dois dos entrevistados foi a questão política, ou seja, segundo eles a participação incipiente está, muitas vezes, relacionada a questão dos representantes destes municípios serem indicados e não eleitos para representarem o município frente a política pública. Neste sentido, essas pessoas fazem parte porque foram indicados e este "fazer parte" é completamente diferente de uma pessoa que se associa por vontade de colaborar e contribuir, ou seja, que "toma parte". Por outro lado, alguns entrevistados destacaram que o ponto forte do Circuito é justamente o contraponto de uma fraca participação, ou seja, é o envolvimento das pessoas que estão participando porque estão envolvidos com o trabalho.

Segundo o entrevistado E a participação é mais efetiva nos municípios que possuem maior visitação turística. $\mathrm{O}$ entrevistado $\mathrm{C}$ concorda ao afirmar que "em 
Ibitipoca já acontece mais, então os moradores ali acreditam mais no turismo". Já os municípios que não têm muita visitação, tendo um maior movimento nas épocas das principais festas, possuem uma participação mais fraca. Emmendoerfer, Silva, Emmendoerfer e Fonseca (2007) colocam que a heterogeneidade entre os municípios que fazem parte de um Circuito Turístico pode comprometer o desenvolvimento em razão do "peso" diferenciado que o turismo exerce nas economias, fazendo com que as ações necessárias para o progresso da atividade sejam relegadas, muitas vezes, a um segundo plano.

Diante dos relatos, foi possível observar que a não participação pode não ser fruto do desinteresse, mas do desconhecimento e do descrédito em relação à política pública, o que impede a efetiva participação. Para Bordenave (2013), a participação é mais genuína e produtiva quando o grupo se conhece bem e se mantém bem informado sobre o que acontece dentro e fora de si, implicando num contínuo processo de criação de conhecimento pelo grupo tanto sobre si mesmo como sobre seu ambiente.

Os entrevistados foram unânimes no que diz respeito à necessidade de mudanças para obtenção de maior participação dos atores sociais locais. No entanto, para fomentar a participação, a cidadania deverá ser resgatada por meio de um processo educativo. A educação deve ser vista como um processo que contribui para capacitar o indivíduo para uma visão crítica da realidade e uma atuação consciente no espaço social, sendo necessário "que a dinâmica social seja conhecida e que nela o engajamento cidadão seja possível, a partir do reconhecimento de sua condição de sujeito social" (IRVING, 2018, p. 60).

Alguns dos entrevistados se posicionaram sobre o que poderia ser feito para obtenção de maior participação da população local no contexto das políticas públicas de turismo. Tal opinião pode ser sintetizada na fala do sujeito C: "é fortalecer a presença dos atores e que as propostas destes atores sejam consideradas e que os próprios atores entendam esta política". As políticas públicas encontram legitimidade e efetividade exatamente neste compromisso com o bem comum, por meio de encontros e diálogo com as pessoas para compreender suas demandas. Por isso devem objetivar "fazer com" e não "para" as pessoas (SAWAYA, 2007).

Contudo, no âmbito do Circuito Turístico Serras de Ibitipoca a participação ainda não se consolidou efetivamente. Torna-se necessário tanto o fortalecimento da participação social, quanto a articulação entre os diferentes atores que compõem o Circuito.

\section{CONSIDERAÇÕES FINAIS}

Em suma, foi possível perceber, no âmbito do Circuito Turísticos Serras de Ibitipoca, que na prática a participação social ainda não se consolidou, apresentando, para tal, diversos desafios. Nem todos os municípios participam efetivamente do Circuito, tal questão justifica-se pela fragilidade institucional no âmbito municipal; questões políticas; heterogeneidade entre os municípios; dificuldade de diálogo e 
articulação; desconhecimento e descrédito em relação à política pública. Verificouse, portanto, a necessidade de se fomentar e fortalecer a participação social a partir da perspectiva de políticas construídas 'com' os atores locais e não 'para' eles. Tal processo implica um planejamento baseado na participação social e nas especificidades de cada localidade.

Apesar da importância do tema da participação social ser ressaltado nas políticas públicas atuais, são limitados os avanços concretos neste sentido. Transformar o debate teórico em ações cotidianas no plano da construção da cidadania e também da ação governamental em planejamento turístico não constitui um obstáculo simples a ser transposto (IRVING, 2018).

Mas torna-se necessário apreender novas formas de participação fomentando a cidadania e a busca de objetivos comuns. É preciso um processo educativo que vise sensibilizar e conscientizar a partir da realidade local, de forma a fortalecer os processos participativos que visem o desenvolvimento do turismo e da localidade como um todo. O turismo não é isento de riscos ou ameaças, no entanto, a comunidade deve conhecê-los e debater sobre estes, a fim de salvaguardar seus interesses e minimizar os efeitos indesejáveis. A partir desta perspectiva pretende-se que a participação dos sujeitos não fique só no plano simbólico e dos discursos, mas atinja o plano real.

Considera-se, portanto, que o desenvolvimento deve partir de diretrizes nas quais pressupõe a participação da população local enquanto sujeitos do processo, propiciando a este um saber sobre si mesmo que o instrumentaliza para análise crítica de sua realidade e para busca permanente de soluções. Dessa forma, poderão agir como protagonistas do processo, apresentando expectativas de mudanças de contextos adversos, construção de novas realidades e transformação social.

Contudo, apesar de ser capaz de lançar luzes e servir para um futuro aprofundamento dos estudos sobre a relação entre turismo, desenvolvimento e participação social, ressalta-se que este estudo apresenta limitações pela amostra abrangida devido à dificuldade de acesso aos diferentes atores que compõem o Circuito, o que implica no resultado da análise.

No entanto, suscita o desenvolvimento de trabalhos que abordem uma temática pertinente, atual e de suma importância. Com isto, indica-se a necessidade de realização de novas pesquisas que visem refletir sobre formas de se tornar o processo de participação efetivo no âmbito das Instâncias de Governança.

\section{REFERÊNCIAS}

BORDENAVE, J. E. D. O que é participação. São Paulo: Brasiliense, 2013.

BRASIL. Ministério do Turismo. Plano Nacional de Turismo 2018-2022. Mais

emprego e renda para o Brasil. 2018. Disponível em: <http://www.turismo.gov.br/ images/pdf/PNT_2018-2022.pdf>. Acesso em: 23 jul. 2020. 
BRASIL. Ministério do Turismo. Programa de Regionalização do Turismo: Diretrizes. 2013.Disponível em: <http://www.turismo.gov.br/sites/default/ turismo/o_ministerio/publicacoes/downloads_publicacoes/PROGRAMA_DE_ REGIONALIZACAO_DO_TURISMO_-_DIRETRIZES.pdf>. Acesso em: 15 de jul. 2020.

BRASIL, Ministério do Turismo. Módulo Operacional 3. Institucionalização da Instância de Governança Regional. 2007. Disponível em: <http://www. regionalizacao.turismo.gov.br/images/roteiros_brasil/institucionalizacao_da_ instancia_de_governanca_regional.pdf>. Acesso em: 23 jul. 2019.

BRASIL. Ministério do Turismo. Introdução à Regionalização do Turismo. 2007. Disponível em: <http://www.ibam.org.br/media/arquivos/estudos/introducao_ turismo.pdf>. Acesso em: 23 jul. 2020.

CIRCUITO SERRAS DE IBITIPOCA. Disponível em: <https://www. circuitoserrasdeibitipoca.com.br/?lightbox=dataltem-iiax3b5x>. Acesso em: 05 ago. 2020.

CRUZ, R. C. A. Política de Turismo e Território. São Paulo: Contexto, 2002.

DEMO, P. Participação é conquista. São Paulo: Cortez, 2001.

EMMENDOERFER, L.; SILVA, L. F. T. B.; EMMENDOERFER, M. L.; FONSECA, P. C. A formação dos circuitos turísticos mineiros: uma política pública descentralizada e democratizante? Revista Acadêmica Observatório de Inovação do Turismo, Rio de Janeiro, v. 2, n.4, p.1-18, 2007. Disponível em: <http://bibliotecadigital.fgv.br/ojs/ index.php/oit/article/view/5686/4400>. Acesso em: 31 ago. 2020.

ENDRES, A. V.; PAKMAN, E. T. A governança das políticas de turismo: o papel dos espaços de participação na perspectiva da análise de redes e da teoria institucional. Revista Brasileira de Pesquisa em Turismo, v. 13, n. 1, p. 1-18, 2019. Disponível em: < https://rbtur.org.br/rbtur/article/view/1431/842>. Acesso em: 28 abr. 2021.

FRATUCCI, A. C. Refletindo Sobre a Gestão dos Espaços Turísticos: perspectivas para as redes regionais de turismo. Turismo em Análise, São Paulo, v. 20, n.3, p. 391-408, 2009. Disponível em: <http://www.revistas.usp.br/rta/article/view/14192>. Acesso em: 31 ago. 2020.

GOHN, M. G M. O protagonismo da sociedade civil: movimentos sociais, ONGs e redes solidárias. São Paulo: Cortez, 2008.

GÓIS, C. W. L. Psicologia Comunitária: atividade e consciência. Fortaleza:

Publicações Instituto Paulo Freire de Estudos Psicossociais, 2005. 
HÔ, P. N. O desenvolvimento endógeno como alternativa: potencialidades e obstáculos ao seu desdobramento. In: MACIEL, T. B. (Org.). Caminhos para o desenvolvimento-Século XXI. Rio de Janeiro: UFRJ/Cátedra UNESCO de Desenvolvimento Durável da UFRJ/EICOS, 2006. p. 35-91.

IRVING, M. Participação, inclusão social e os Objetivos de Desenvolvimento Sustentável: por uma nova ética em projetos turísticos. In: IRVING, M.A.; AZEVEDO, J.; LIMA, M. A. G. Turismo: ressignificando sustentabilidade. Rio de Janeiro: Folio Digital: Letra e Imagem, 2018. p. 57-90.

. Áreas de Protegidas e Inclusão Social: Construindo novos significados. Rio de Janeiro: Fundação Bio-Rio, 2006.

. Turismo como instrumento para desenvolvimento local: Entre a potencialidade e a utopia. In: D'AVILA NETO, M. I.; PEDRO, R. (Org.). Tecendo o desenvolvimento:saberes, gênero, ecologia social Rio de Janeiro: MAUAD Bapera Editora, 2003, p. 167-184.

Construindo um modelo de planejamento turístico de base comunitária: um estudo de caso. Rio de Janeiro: UFRJ, 1999.

IRVING, M. A. BURSZTYN, I.; SANCHO, A.; MELO, G. M. Revisitando significados em sustentabilidade no planejamento turístico. Caderno Virtual de Turismo, v.5, n.4, p. 1-7, 2005. Disponível em: <http://www.ivt.coppe.ufrj.br/caderno/index.php?journal=caderno\&page=article\&op=view\&path\%5B\%5D=98\&path\%5B\%5D=93>. Acesso em: 14 dez. 2018.

LOUREIRO, C. F. B.; MARCUS, A.; FRANCA, N. Educação Ambiental e Gestão Participativa em Unidades de Conservação. Rio de Janeiro: IBAMA / IBASE, 2003.

MINAS GERAIS, Secretaria do Estado de Turismo e Esportes. Orientações para o Planejamento e Gestão Municipal do Turismo em Minas Gerais, 2014.

Disponível em: <http://www.turismo.mg.gov.br/images/stories/circuitos/ferramenta planejamento/orientacoes-para-o-planejamento-e-gestao-municipal-do-turismosetur-mg-2014.pdf>. Acesso em: 13 jul. 2020.

MINAS GERAIS, Secretaria de Estado de Turismo de Minas Gerais. O que é um Circuito Turístico? Disponível em: http://www.turismo.mg.gov.br/circuitosturisticos/informacoes-administrativas. Acesso em: 3 de jul. 2020.

MINAYO, M. C. S. O desafio da pesquisa social. In: MINAYO, M.C.S.; DESLANDES, S.F.; GOMES, R. Pesquisa Social: teoria, método e criatividade. Petrópolis: Vozes, 2009. p. 9-30. 
MINAYO, M. C. S. O desafio do conhecimento: pesquisa qualitativa em saúde. São Paulo: Hucitec, 2008.

PINHEIRO, I. F. S.; MARACAJÁ, K. F. B.; CHIM-MIKI, A. F. Política Pública de Regionalização do Turismo: um estudo sobre a participação social no polo de turismo Seridó. Turismo Visão e Ação. v.22, n.1, p. 162-184, 2020. Disponível em: $<$ https://www.scielo.br/pdf/tva/v22n1/1983-7151-tva-22-01-00162.pdf >. Acesso em: 09 abr. 2021.

SACHS, I. Desenvolvimento: includente, sustentável, sustentado. Rio de Janeiro: Garamond, 2004.

A lógica do desenvolvimento. Revue Internationale des Sciences Sociales, v. L, n. 3, p. 1-7, 1998.

. Em busca de novas estratégias de desenvolvimento. Estudos Avançados, v. 9, n. 25, p. 29-63, 1995.

SANTOS, B. S. Produzir para viver. Rio de Janeiro: Civilização Brasileira, 2005.

SANTOS, M. S.; ÁVILA, M. Planejamento participativo: uma análise do turismo de Uruçuca (BA) a partir da ótica dos residentes. Caderno Virtual de Turismo, v.17, n. 1, p. 30-45, 2017. Disponível em: <http://www.ivt.coppe.ufrj.br/caderno/index.php/ caderno/article/view/984/509 >. Acesso em: 28 abr. 2021.

SAWAYA, A. L. Políticas públicas: pontos de método e experiências. Estudos Avançados, v. 20, n.56, p. 130-147, 2007.

SEN, A. Desenvolvimento como liberdade. São Paulo: Companhia das Letras, 2000.

SOUZA, M. L. Desenvolvimento de comunidade e participação. São Paulo: Cortez, 2004.

Recebido em: 14-08-2020.

Aprovado em: 01-05-2021. 
$S$ 